\title{
THERMOMAGNETIC PROCESSING OF ALUMINUM ALLOYS DURING HEAT TREATMENT
}

\author{
David Weiss \\ Eck Industries, Inc, Manitowoc, USA \\ Bart Murphy, Michael J. Thompson, Hunter B. Henderson, Orlando Rios, Gerard M. Ludtka, and \\ Michael S. Kesler \\ Oak Ridge National Laboratory, Oak Ridge, USA \\ Aurelien Perron \\ Lawrence Livermore National Laboratory, Livermore, USA
}

Copyright (C) 2020 The Author(s)

https://doi.org/10.1007/s40962-020-00460-z

Abstract

\begin{abstract}
Processing materials under magnetic fields is an underexplored technique to improve structure and mechanical properties in metals and alloys. Magnetic fields can alter phase stability, modify diffusion characteristics, and alter material flow substantially. In castings, magnetic fields can be used during melting of the alloy, during solidification, or during postprocessing operations such as heat treatment to achieve structural changes. This work investigates the effectiveness of thermomagnetic processing during heat
\end{abstract}

treatment of $\mathrm{Al}$ alloys containing in the $\mathrm{Al}-\mathrm{Cu}, \mathrm{Al}-\mathrm{Si}-\mathrm{Cu}$, and $\mathrm{Al}-\mathrm{Mg}-\mathrm{Ce}$ systems. We demonstrate an improvement in mechanical properties and a reduction in required heat treatment times for all alloys.

Keywords: aluminum alloys, heat treatment, magnetic field processing, hot isostatic pressing

\section{Introduction}

Work in ferrous materials has demonstrated that high magnetic field processing (HMFP) can induce meaningful changes in kinetics, phase equilibria, and solubility limits in the solid state. ${ }^{1-3}$ These processing routes can result in modified microstructures that, for example, retain alloying elements in solution. This potentially negates the need for a solution heat treatments and/or increase maximum solid solubility limits, improving the strength of the alloy. Though the strongest thermodynamic effects are found in materials with in ferro- or ferrimagnetic phases below their

This manuscript has been authored by UT-Battelle, LLC, under contract DE-AC05-00OR22725 with the US Department of Energy (DOE). The US government retains and the publisher, by accepting the article for publication, acknowledges that the US government retains a nonexclusive, paid-up, irrevocable, worldwide license to publish or reproduce the published form of this manuscript, or allow others to do so, for US government purposes. DOE will provide public access to these results of federally sponsored research in accordance with the DOE Public Access Plan (http://energy.gov/ downloads/doe-public-access-plan).
Curie point, nonmagnetic materials such as $\mathrm{Al}$ alloys can also be modified substantially by HMFP.

The Al-Cu-based 2xx alloy series has excellent mechanical properties at both room and elevated temperature, but in the as-cast state significant amounts of $\mathrm{Cu}$ segregation require a solution treatment. A long (8-12 h), high-temperature $\left(510-530{ }^{\circ} \mathrm{C}\right)$ solution treatment is required to dissolve the $\mathrm{Al}-\mathrm{Cu}$ intermetallics. After quenching to a supersaturated solid solution, a low-temperature $\left(\sim 160{ }^{\circ} \mathrm{C}\right)$ aging treatment is used to form fine strengthening precipitates. If HMFP can retain more of the $\mathrm{Cu}$ in the as-cast dendrites, the energy-intensive solution heat treatment could be reduced or potentially eliminated.

$3 \mathrm{xx}$ series alloys are currently used for the production of automotive cylinder heads produced by Eck Industries. Existing alloys like 319, which contain $6 \% \mathrm{Si}$ and $3.5 \% \mathrm{Cu}$, are capable of only moderate room temperature and elevated temperature strength. There is high potential to reach strength targets in $3 \mathrm{xx}$ series alloys that contain both high levels of $\mathrm{Si}$ (up to 9\%) and $\mathrm{Cu}$ (up to 5\%). Conventional 
treatment of this type of alloy is especially difficult as the $\mathrm{Cu}$ content requires long solution treatment times, which can cause coarsening of the Si particles. The accelerated kinetics of magnetic processing may allow large amounts of $\mathrm{Cu}$ into solution in times short enough to prevent coarsening of the Si particles.

HMFP exploration into Al alloys can reveal the threshold magnetic field strengths required to shorten processing times while giving equivalent or better mechanical properties. In this manuscript, HMFP of both a $2 x x$ series Al$\mathrm{Cu}$ (A206 and 242) and a 3xx series Al-Si-Cu (355) alloys is discussed. Additionally, the effect of magnetic field processing on $\mathrm{Al}-8 \mathrm{Ce}-10 \mathrm{Mg}$ alloy, developed in an Eck/ Oak Ridge National Laboratory collaboration, was explored. Al-Ce- $\mathrm{X}^{4}$ alloy systems hold a significant promise of improved thermal stability and high-temperature mechanical properties ${ }^{5,6}$ over the A206 alloy system. These new alloys exhibit elevated temperature strength up to $300^{\circ}$ $\mathrm{C}$ and microstructural stability up to $500{ }^{\circ} \mathrm{C}$.

\section{Experimental Procedure}

To evaluate the new HMFP processing method, Al alloy tensile test bars of series $2 \mathrm{xx}$ and $3 \mathrm{xx}$ of standard chemistries, which were obtained in the as-cast and T4 (solution treated only) conditions, underwent thermomagnetic processing and were compared to the T7 condition (solution treatment plus aging). Additionally, cast Al-Ce alloy samples underwent thermomagnetic processing. Thermomagnetic processing was conducted in 5-in. diameter, vertical warm-bore 9-T superconducting magnet system with a 9-in. long uniform DC magnetic field zone, produced by American Magnetics, Inc., and operated at Oak Ridge National Laboratory in the Advanced Processing Laboratory. That system is shown in Figure 1. Inductive heating of a graphite susceptor approximately $2 \mathrm{in}$.

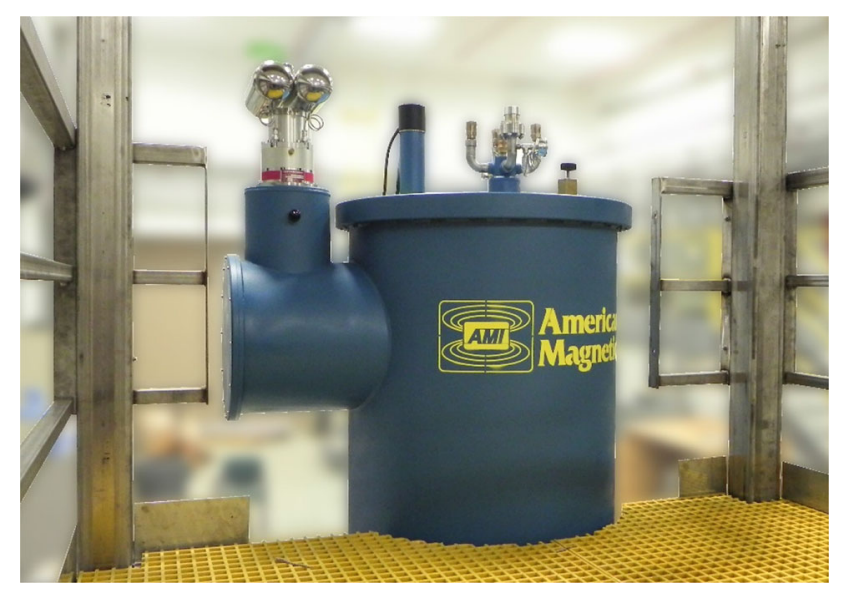

Figure 1. ORNL's 5-in. diameter, vertical warm-bore 9-T superconducting magnet system used for the Al thermomagnetic processing experiments.
(50 mm) outer diameter (OD) and 1.25 in. (32 mm) inner diameter (ID) was used to provide uniform heating to each sample. The power supply operated at a frequency of $165 \mathrm{kHz}$ and provided 20-100 Amps of current, amounting to a skin depth of $<4 \mathrm{~mm}$ into the outside of the graphite susceptor (conductivity $=106,000 \mathrm{MHO} / \mathrm{m}$ ), resulting in adequate shielding of the sample from the induction coil. The susceptor was contained in a 2.2-in. ID closed end quartz tube and positioned in a custom induction heating coil insert positioned inside the magnet bore in the uniform magnetic field zone. Temperature was determined and controlled with an S-type thermocouple in direct contact with the sample and another in contact with the susceptor, where initial experiments were conducted to determine the time for a sample to achieve steady state. Once heating parameters were determined, the induction furnace was held constant and monitored with the susceptor thermocouple to ensure consistency. A carbon fiber thread was tied to each sample as a means of extraction for the rapid water immersion quench immediately following the solution heat treatment. The water quench consisted of a fourgallon reservoir of room temperature water. For samples that required aging, the cooled sample was removed from the bath and returned to the susceptor for a low-temperature treatment. The T4 and T7 nomenclature used above corresponds to standard temper practices and designations as defined by the Aluminum Association.

A number of test conditions and variations of HMFP were evaluated, which are outlined in Table 1. The as-cast samples underwent a solution treatment at either $510^{\circ} \mathrm{C}$ or $530{ }^{\circ} \mathrm{C}$ for $2 \mathrm{~h}$. In this experiment aging times for solutiontreated samples in the T4 condition were varied among $30 \mathrm{~min}, 1 \mathrm{~h}$ and $2 \mathrm{~h}$ to determine the impact of reduced treatment times during exposure to the magnetic field. Samples for microstructural evaluation were prepared using standard metallographic techniques and were observed in optical microscopy and a Hitachi S4700 field

Table 1. Summary of Processing Conditions for Various Alloys in This Study

\begin{tabular}{ll}
\hline Alloy ID & Processing conditions \\
\hline $\begin{array}{l}\text { A206 T4 } \\
\text { Standard }\end{array}$ & $10 \mathrm{~h}$ at $530^{\circ} \mathrm{C}\left(985^{\circ} \mathrm{F}\right), \mathrm{NF}$ \\
A206 T7 & $10 \mathrm{~h}$ at $530^{\circ} \mathrm{C}\left(985^{\circ} \mathrm{F}\right), \mathrm{NF} ; 200^{\circ} \mathrm{C}, 4 \mathrm{~h}, \mathrm{NF}$ \\
$\quad$ Standard & \\
A206-T4 & $510^{\circ} \mathrm{C}, 2 \mathrm{~h}, 9 \mathrm{~T}, \mathrm{WQ}$ \\
A206-T7 & $530^{\circ} \mathrm{C}, 2 \mathrm{~h}, 9 \mathrm{~T}, \mathrm{WQ} ; 20{ }^{\circ} \mathrm{C}, 2 \mathrm{~h}, 9 \mathrm{~T}, \mathrm{FC}$ \\
242 & $516^{\circ} \mathrm{C}, 2 \mathrm{~h}, 9 \mathrm{~T}, \mathrm{WQ} ; 205^{\circ} \mathrm{C}, 1 \mathrm{~h}, 9 \mathrm{~T}, \mathrm{FC}$ \\
355 & $527{ }^{\circ} \mathrm{C}, 2 \mathrm{~h}, 9 \mathrm{~T}, \mathrm{WQ} ; 154^{\circ} \mathrm{C}, 1 \mathrm{~h}, 9 \mathrm{~T}, \mathrm{FC}$ \\
8Ce10Mg & $500^{\circ} \mathrm{C}, 2 \mathrm{~h}, 2,5$, or $9 \mathrm{~T}, \mathrm{WQ} ; 155^{\circ} \mathrm{C}, 1 \mathrm{or}$ \\
& $4 \mathrm{~h}, 2,5$, or $9 \mathrm{~T}, \mathrm{FC}$ \\
\hline
\end{tabular}

$W Q$ water quench, $N F$ no field, $F C$ furnace cool 
emission scanning electron microscope (FEG-SEM) in the backscattered electron (BSE) imaging mode. Processed ASTM B108 samples were then tested for ultimate tensile strength (UTS), yield strength (YS) and \% elongation using a United STM-100KN tensile testing machine with a crosshead speed of $0.5 \mathrm{in} . / \mathrm{min}$. Conventional mechanical test methods and results for all alloys are shown in Table 2. Included in these data are reference data for conventional heat treatment processing, as well as data gathered on the $\mathrm{Al}-8 \mathrm{Ce}-10 \mathrm{Mg}$ alloy through the Critical Material Institute (CMI) program. ${ }^{4}$ The CMI data are for a conventional T6 temper heat treatment and for a sample that received a hot isostatic pressing (HIP) step that is generally used on materials to reduce porosity and increase density.

\section{Results and Discussion}

\section{2xx Alloys}

Mechanical properties for all alloys and test conditions are summarized in Table 2 and displayed in Figure 2. Both conventionally heat-treated and thermomagnetically processed bars were produced from the same lot of material and cast into a permanent mold using a standard ASTM

\section{Table 2. Mechanical Property Results for All Samples} Evaluated

\begin{tabular}{|c|c|c|c|c|}
\hline Alloy & Field & UTS (ksi) & YS (ksi) & $\%$ El \\
\hline As-cast A206 & NF & 39.5 & 27.5 & 5 \\
\hline A206 T4 Standard & NF & 58.3 & 37.7 & 12.6 \\
\hline A206 T7 Standard & NF & 54.8 & 45.8 & 4.6 \\
\hline A206-T4 & $9 \mathrm{~T}$ & 55.9 & 47.8 & 3.5 \\
\hline \multirow[t]{2}{*}{ A206-T7 } & $9 \mathrm{~T}$ & 58.2 & 51.1 & 3.0 \\
\hline & $9 \mathrm{~T}$ & 62.8 & 50.0 & 5.5 \\
\hline \multirow[t]{2}{*}{242} & $9 \mathrm{~T}$ & 39.5 & 38.4 & 1.2 \\
\hline & $9 \mathrm{~T}$ & 41.4 & 38.8 & 1.25 \\
\hline 242-T77 Standard & NF & 35.0 & 26.1 & 1.8 \\
\hline \multirow[t]{2}{*}{355} & $9 \mathrm{~T}$ & 41.2 & 28.8 & 3.28 \\
\hline & $9 \mathrm{~T}$ & 41.6 & 29.1 & 2.3 \\
\hline \multirow[t]{2}{*}{ 355-T6 Standard } & NF & 41.6 & 30.1 & 4 \\
\hline & $2 \mathrm{~T}$ & 35.2 & 30.2 & 1.6 \\
\hline \multirow[t]{3}{*}{$8 \mathrm{Ce} 10 \mathrm{Mg}-1 \mathrm{~h}$ age } & $5 \mathrm{~T}$ & 37.4 & 30.5 & 2.47 \\
\hline & $5 \mathrm{~T}$ & 37.5 & 30.5 & 1.48 \\
\hline & $9 \mathrm{~T}$ & 36.5 & 30.5 & 1.15 \\
\hline \multirow[t]{2}{*}{$8 \mathrm{Ce} 10 \mathrm{Mg}-4 \mathrm{~h}$ age } & $9 \mathrm{~T}$ & 37.3 & 30.6 & 1.31 \\
\hline & $9 \mathrm{~T}$ & 38.1 & 30.6 & 1.13 \\
\hline $8 \mathrm{Ce} 10 \mathrm{Mg}-\mathrm{T6}^{4}$ & 0 & 32.0 & 24.5 & 2 \\
\hline \multicolumn{5}{|l|}{ CMI Project Typical } \\
\hline 8Ce10M HIP $\left(^{*}\right)$ & 0 & 38.0 & 30.8 & 1.5 \\
\hline
\end{tabular}

UTS ultimate tensile strength, YS yield strength, El elongation
B108 test bar mold. All the bars in the T4 condition were tested after 7 days at room temperature. Test bars produced to the $\mathrm{T} 7$ temper were held for a minimum of $24 \mathrm{~h}$ between solution and age. The bars for both $\mathrm{T} 4$ and $\mathrm{T} 7$ were from the same production lot of castings. For A206 samples supplied in the as-cast condition, effective solutionizing occurred within $2 \mathrm{~h}$ under the $9 \mathrm{~T}$ magnetic field, $80 \%$ faster than the standard 10-h cycle time. This was verified through the mechanical properties data (Table 2, Figure 2 left), which show that UTS above $55 \mathrm{ksi}(379 \mathrm{MPa})$ and YS above $47 \mathrm{ksi}$ (324 MPa) can be achieved after significantly reduced solution processing times when a 9-T magnetic field is applied. This improvement persisted with aging in the magnetic field, as A206-T7 processed in the magnetic field was stronger than the standard alloy aged for twice the time and the $5 \mathrm{X}$ longer solution treatment.

Alloy 242 was thermomagnetically processed via a solution $\left(516{ }^{\circ} \mathrm{C}\right.$ for $\left.2 \mathrm{~h}\right)$ and aging $\left(20{ }^{\circ} \mathrm{C}\right.$ for $\left.1 \mathrm{~h}\right)$ treatment in a 9-T field. Both conventionally heat-treated and thermomagnetically processed bars were produced in a green sand mold using a standard ASTM B26 test bar mold from the same lot of material. In Figure 3, optical micrographs display the untreated (left) and thermomagnetically processed (right) microstructures. The most notable effect is in the dissolution of the $\mathrm{Cu}$-rich particles (eutectic phase) which previously decorated the grains in the as-cast condition. Normally, long (8-12 h), high-temperature $\left(530{ }^{\circ} \mathrm{C}\right.$ ) solution treatment is required to dissolve the $\mathrm{Cu}$, which is then captured in a supersaturated solid solution during quenching, followed by a 4-h aging or precipitation treatment at $200{ }^{\circ} \mathrm{C}$. HMFP of this alloy accelerates that dissolution process and yields more solute in solid solution to form finer and more copious strengthening precipitates that would increase strength over non-HMFP processed samples. Compared to conventionally heat-treated A242T77 the yield strength of the HMFP samples is $48 \%$ higher, while elongation remains above $1 \%$. The combination of higher strength and equal ductility in a cast product suggests that a fine precipitate likely formed during aging due to the more homogeneous redistribution of solute atoms in the matrix during the solution treatment in the field.

\section{3xx Alloy}

Alloy 355 in the $\mathrm{T} 6$ condition was also thermomagnetically processed via a solution $\left(527^{\circ} \mathrm{C}\right.$ for $\left.2 \mathrm{~h}\right)$ and aging $\left(154{ }^{\circ} \mathrm{C}\right.$ for $\left.1 \mathrm{~h}\right)$ treatment in a 9-T field. Both conventionally heat-treated and thermomagnetically processed bars were produced in permanent mold using a standard ASTM B108 test bar mold from the same lot of material. The mechanical properties for conventionally heat-treated bars were $31.6 \mathrm{ksi}$ (208 MPa) YS, $43.4 \mathrm{ksi}(287 \mathrm{MPa})$ UTS, and $4 \%$ elongation, so the HMFP technology achieved equivalent UTS and YS at $25 \%$ of the solution time for both the solution and aging treatments (Table 2). 

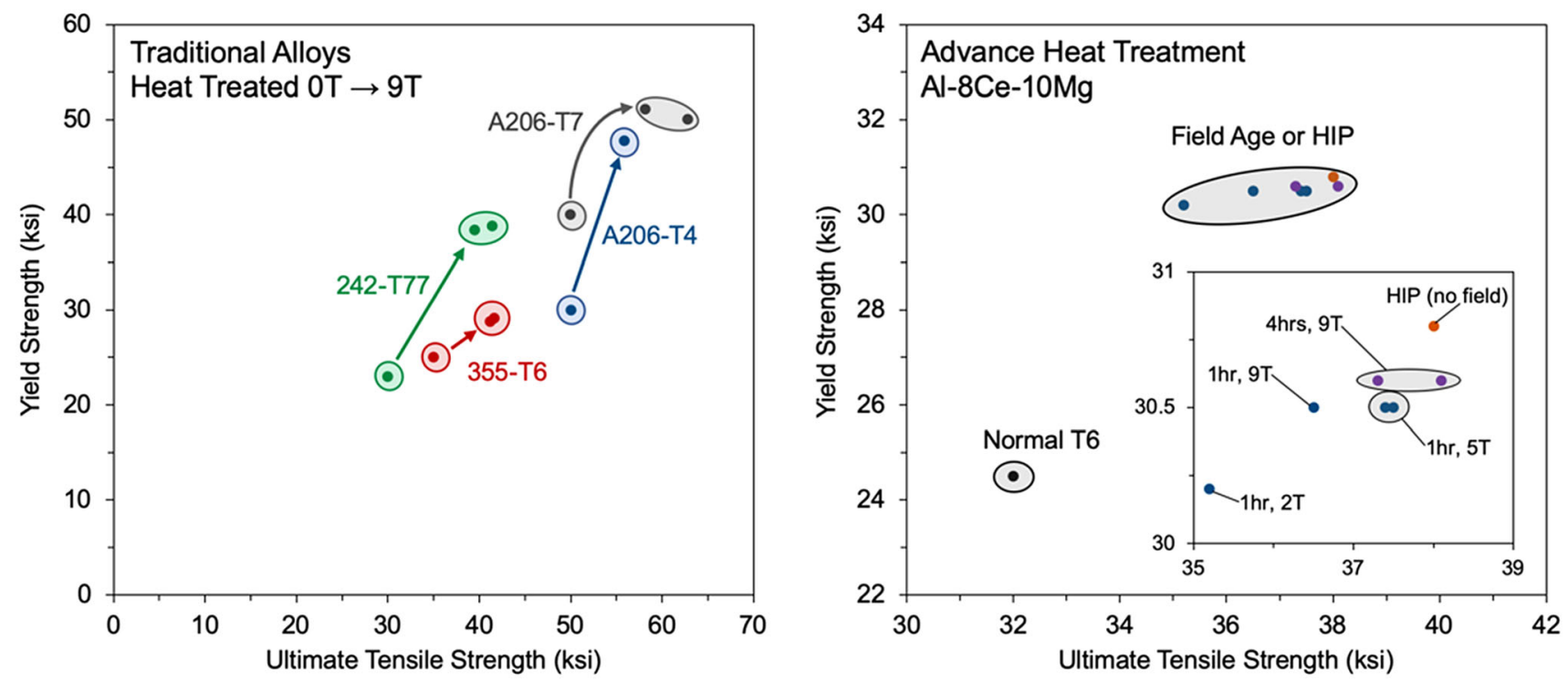

Figure 2. Mechanical property comparison of conventional and HMFP heat treatments for traditional (left) and Al$\mathrm{Ce}$ (right) alloys. The inset (right) is an expanded view of the field age or HIP area of the Al-8Ce-10Mg data.
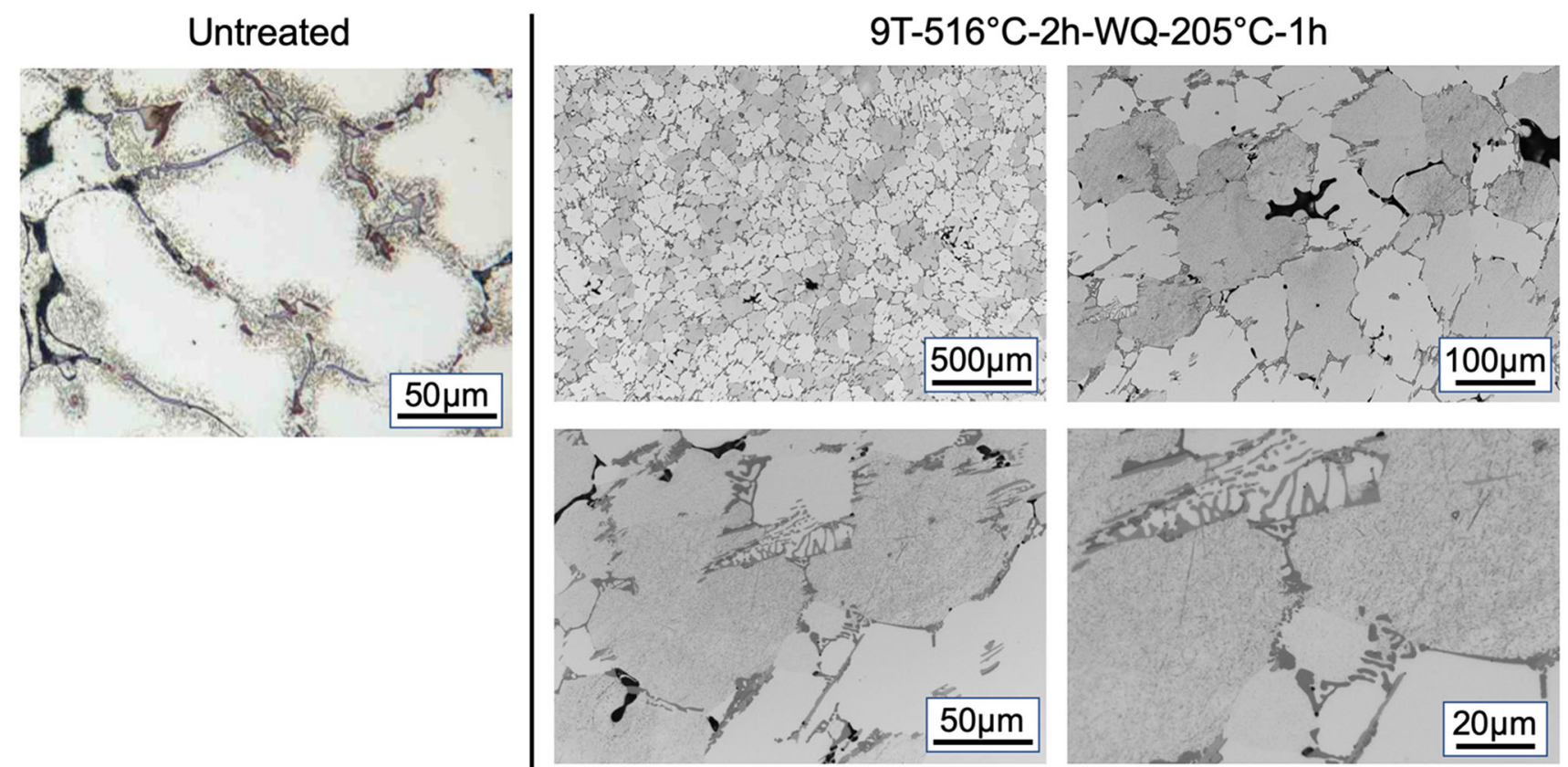

Figure 3. Optical micrographs of alloy 242 in the untreated (left) and thermomagnetically processed (right) conditions.

In Figure 4, optical micrographs display the as-cast (left), conventionally heat-treated (middle), and thermomagnetically processed (right) microstructures. The phase fraction of grain boundary phases in the conventionally processed and HMFP conditions is statistically identical at 0.06 area fraction, as measured in ImageJ software. This is due to the lack of solubility of $\mathrm{Si}$ in the Al matrix. The primary grain boundary phase (dark contrast) is a Si-rich phase, and another phase (gray contrast), also found at the grain boundaries, was included in the phase fraction measurement and did not change in proportion in either condition.
Upon conventional heat treatment, the Si-rich phase (darker contrast) underwent significant spheroidization and some coarsening compared with the as-cast microstructure. Spheroidization during heat treatment was less pronounced in the HMFP specimen, and less coarsening was observed both owed to the significantly shorter time held at the solutionizing temperature. To determine the difference between these samples, the particles were analyzed with ImageJ software. Figure 5 shows density plots of the particle circularity ( 1 being a perfect circle, 0 being a line) versus the reduced particle diameter (the diameter of a 

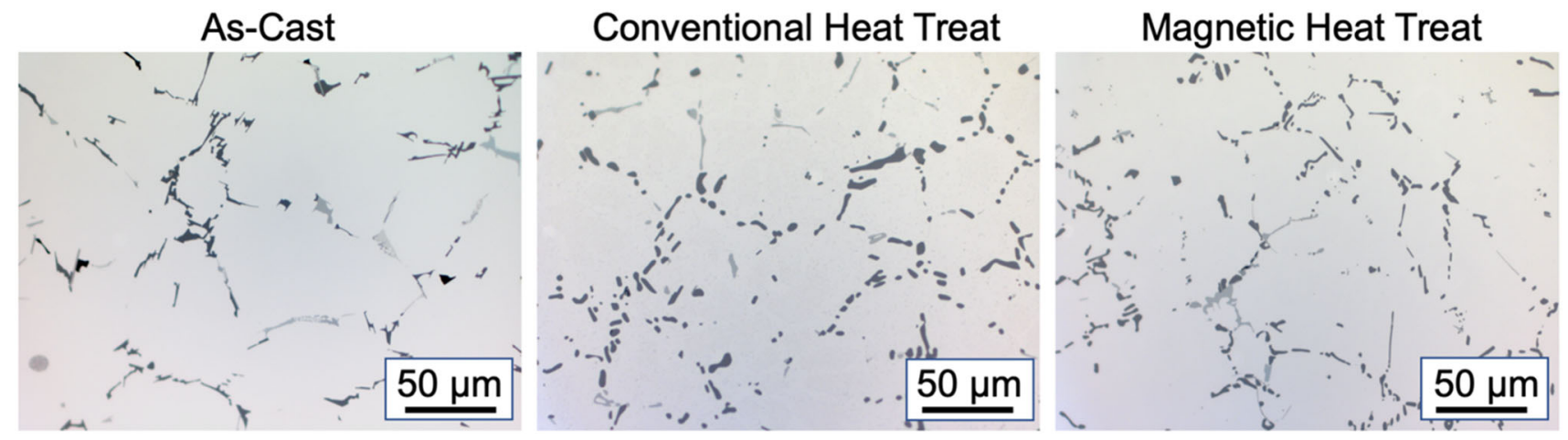

Figure 4. Optical micrographs of alloy 355 as-cast (left), conventionally heat-treated (middle), and thermomagnetically processed (right).

circle having the same area of the particle) of the darker phase for the conventionally (left) and thermomagnetically (right) heat-treated conditions. It should be noted that this particular analysis was only valid for particles above $1 \mu \mathrm{m}$ due to the resolution of the micrographs used. These data show particles with the distribution trending to smaller particles for the HMFP microstructure, supporting the qualitative observation of particle coarsening in the conventional no-field case. Morphologically, the microstructure of the HMFP specimen appears to be somewhere between that of the as-cast and the conventionally treated sample. For the no-field heat-treated condition, the circularity is much greater over the particle distribution and the highest particle density spans from $\sim 2$ to $4 \mu \mathrm{m}$, while for the HMFP specimen, the circularity is highest for particles of $2.5 \mu \mathrm{m}$ and below, and the number density is more diffused over both circularity and reduced diameter. The highest number density for HMFP trends to the smaller reduced particle diameter. These data indicate that HMFP has the added effect of limiting spheroidization and coarsening while also effectively solutionizing. HMFP has been shown to limiting kinetic effects, ${ }^{7,8}$ such as nucleation and growth, in other materials, but a more rigorous microstructural study is necessary to elucidate those effects in $\mathrm{Al}$ alloys.

\section{Al-Ce Alloy}

A parametric study involving different high magnetic field strength levels $(2,5$, and $9 \mathrm{~T})$ was conducted on the Al$8 \mathrm{Ce}-10 \mathrm{Mg}$ alloy. This was done to determine the lowest magnetic field strength necessary to achieve the performance enhancements observed at the 9-T level. The data in Table 2 indicate that the 2-T level provides an industrially beneficial impact almost comparable to the 5-T level that exhibited the highest strength and ductility improvements in this study. From a commercial implementation/scalability perspective, the lowest magnetic field strength to achieve a cost-effective performance enhancement translates to the lowest cost superconducting magnet system required for the heat-treating process. The improvement observed at the 2-T level suggests that the majority of the property enhancement occurs approaching a threshold value of field strength that contributes most to the dissolution of solute during the solution heat treatment cycle,
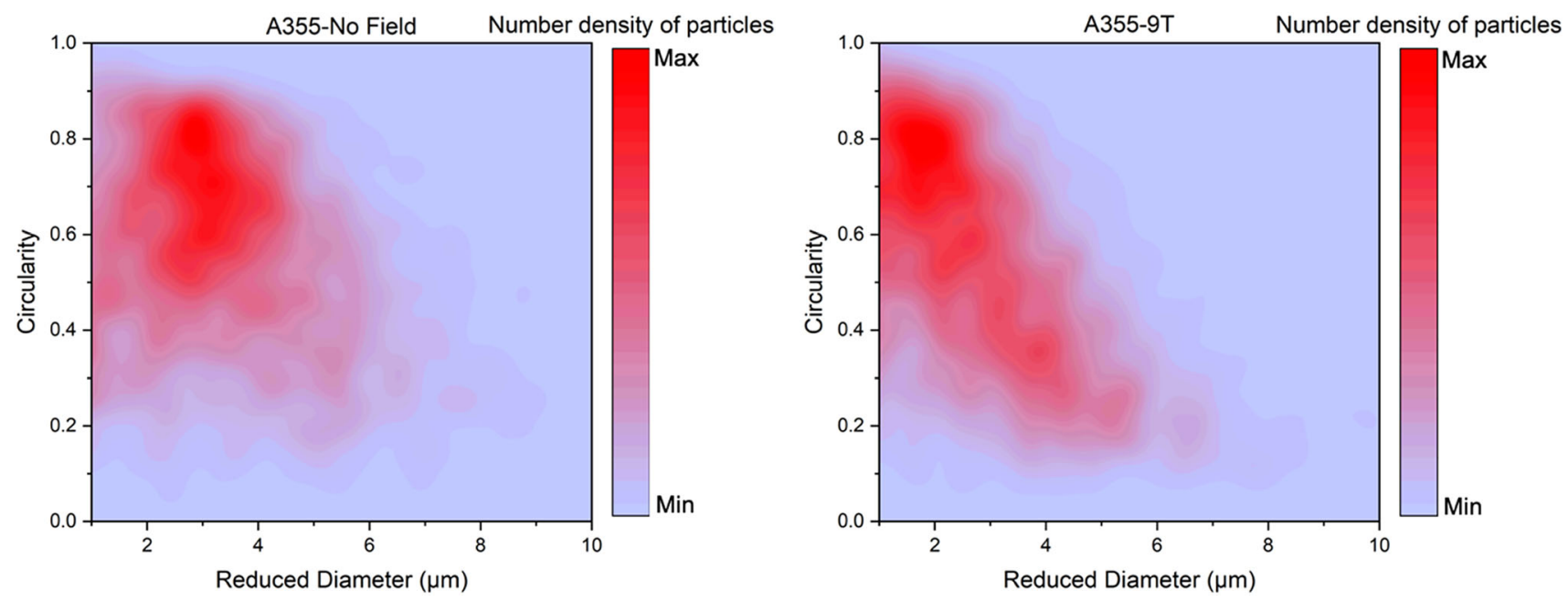

Figure 5. Circularity versus reduced diameter plotted as number density of particles for alloy 355 of the darker phases after conventional (left) and thermomagnetic (right) heat treatment. 
accelerates the solution heat-treating and aging heat treatment processes, and achieves higher strengths after final aging in a field.

Since comparable results were observed at all 3 field strength levels, the microstructural evaluation of the 2-T sample will be discussed in this paper and will be compared with an as-cast sample as well as with a sample that received a HIP treatment $\left(0 \mathrm{~T}, 100 \mathrm{MPa}, 432{ }^{\circ} \mathrm{C}, 3\right.$, or $21 \mathrm{~h})$. This particular $\mathrm{Al}-8 \mathrm{Ce}-1 \mathrm{Mg}$ sample was thermomagnetically processed via a solution $\left(500{ }^{\circ} \mathrm{C}\right.$ for $\left.2 \mathrm{~h}\right)$ and aging $\left(155^{\circ} \mathrm{C}\right.$ for $\left.1 \mathrm{~h}\right)$ treatment in a $2-\mathrm{T}$ field. In Figure 6 , optical (top) and SEM BSE (bottom) micrographs show the effect of magnetic processing (right) compared to the HIP (middle) and as-cast (left) conditions. The HIP and magnetic field treatments result in similarly enhanced tensile properties (Table 2), and the effects on microstructure are not evident at these magnifications. Both the HIP (bottom middle in Figure 6) and the magnetically processed sample (bottom right in Figure 6) appear similar to the as-cast microstructure (bottom-left in Figure 6). Optical micrographs in Figure 7 show that there is some evidence of grain boundary pinning of $\mathrm{Al}$ grains in the samples processed in the magnetic field. Further investigation is necessary to understand the microstructure at higher magnification. As is the case for tempering age-hardening Al alloys, the mechanisms for the enhanced mechanical properties in the magnetically processed samples likely arise from microstructural features at a finer (tens of nanometers) scale, not observable with optical microscopy or SEM. The literature in the past decade ${ }^{9,10}$ suggests that a low-frequency magnetic field and magnetic fields in general, from a grain boundary engineering perspective, can decrease grain boundary segregation, produce more homogeneous distribution of hardening solute in the matrix phase, and result in more copious precipitation potentially facilitating the property enhancements observed in this investigation.

A noteworthy microstructural observation in the HIP and 2-T conditions was the effect of heat treatment on a detrimental Fe-rich phase that is present due to the small $\mathrm{Fe}$ concentration in the $\mathrm{Al}-8 \mathrm{Ce}-10 \mathrm{Mg}$ alloy. Figure 8 shows the morphology of this phase in the various conditions. The phase has a needle-like morphology that formed upon solidification in the cast structure. In the HIP condition at $432{ }^{\circ} \mathrm{C}$, this phase began to agglomerate with the adjacent needles after $3 \mathrm{~h}$ and fully agglomerated and spheroidized after $21 \mathrm{~h}$, while after thermomagnetic processing at $500{ }^{\circ} \mathrm{C}$ for $2 \mathrm{~h}$, this phase remained needle-like, similar to the cast structure. Because HMFP is being investigated for both energy savings during the heat-treating process by dramatically reducing processing time and demonstrating enhanced tensile properties, processing times on the order of $21 \mathrm{~h}$ have not been evaluated.

Throughout this discussion of $\mathrm{Al}-8 \mathrm{Ce}-10 \mathrm{Mg}$ and other alloys, accelerated dissolution of solutionizable elements during the thermomagnetic processing treatments has been suggested as a mechanism for improved aging response, resulting in finer and more copious strengthening precipitates. This concept is supported by looking at the predicted phases present in this alloy as a function of temperature as shown in the CALPHAD-based plots depicted in Figure 9. Calculations have been made using the Thermo-Calc software and a user-defined thermodynamic database. The
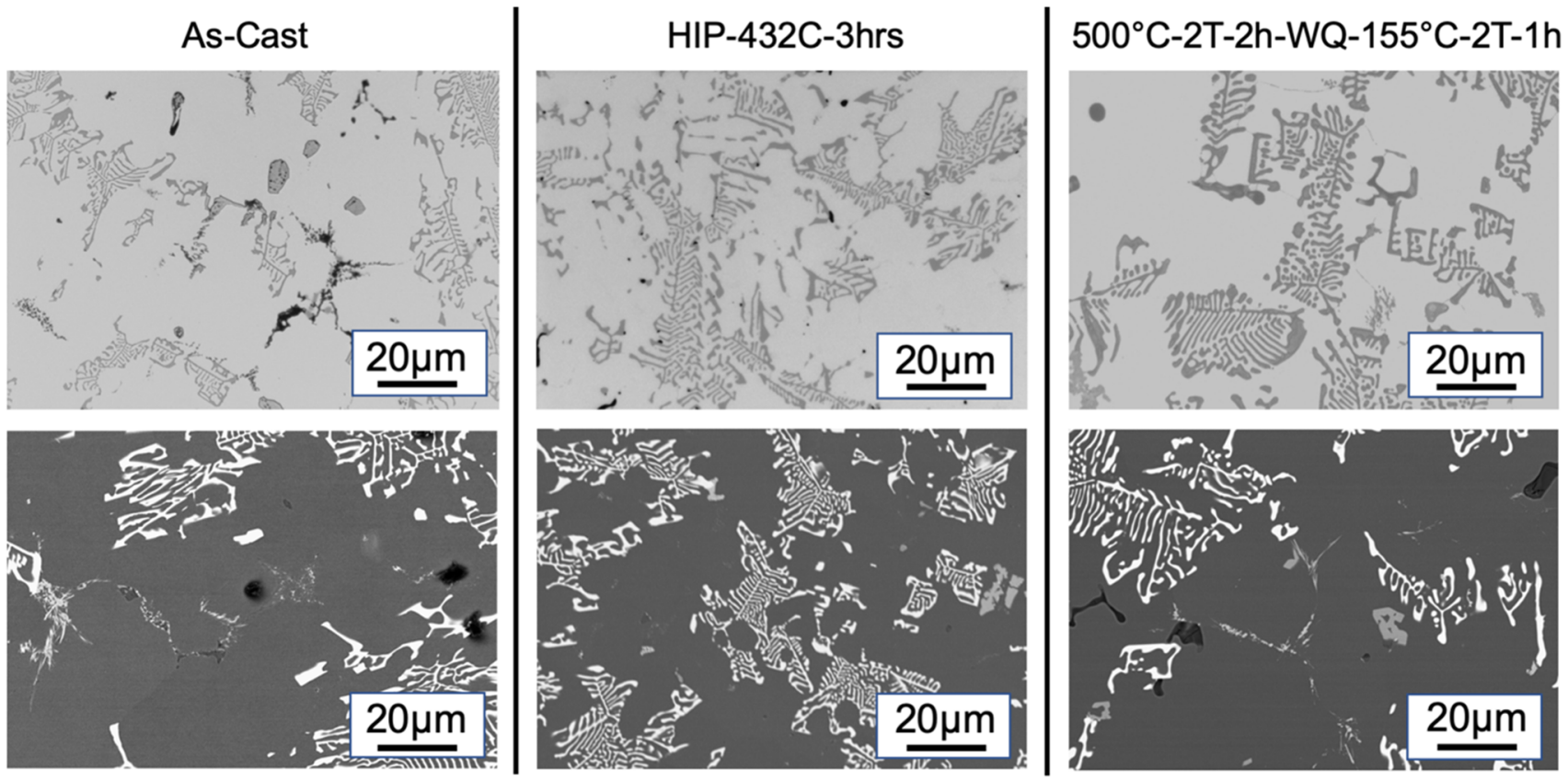

Figure 6. Optical (top) and SEM BSE (bottom) micrographs of alloy Al-8Ce-10Mg in the as-cast (left), HIP (middle), and thermomagnetically processed (right) conditions 


\section{$500^{\circ} \mathrm{C}-2 \mathrm{~T}-2 \mathrm{~h}-\mathrm{WQ}-155^{\circ} \mathrm{C}-2 \mathrm{~T}-1 \mathrm{~h}$}
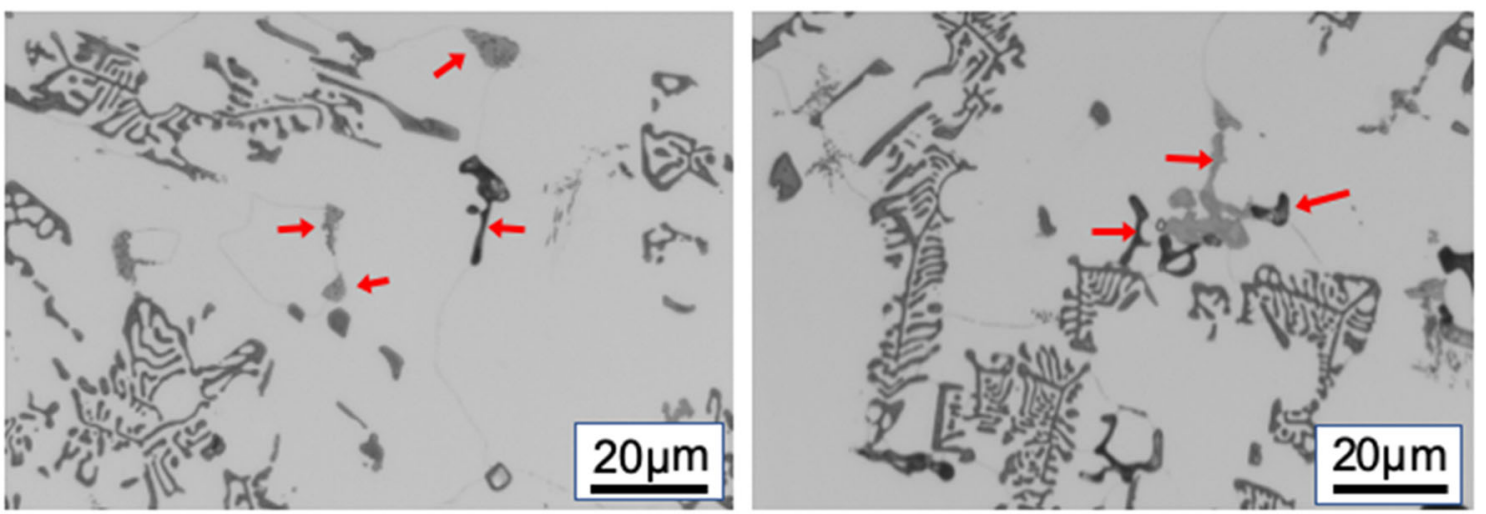

Figure 7. Optical micrographs of thermomagnetically processed alloy Al-8Ce-10Mg showing pinning (arrows along faint grain boundaries) of some Al/Al grain boundaries
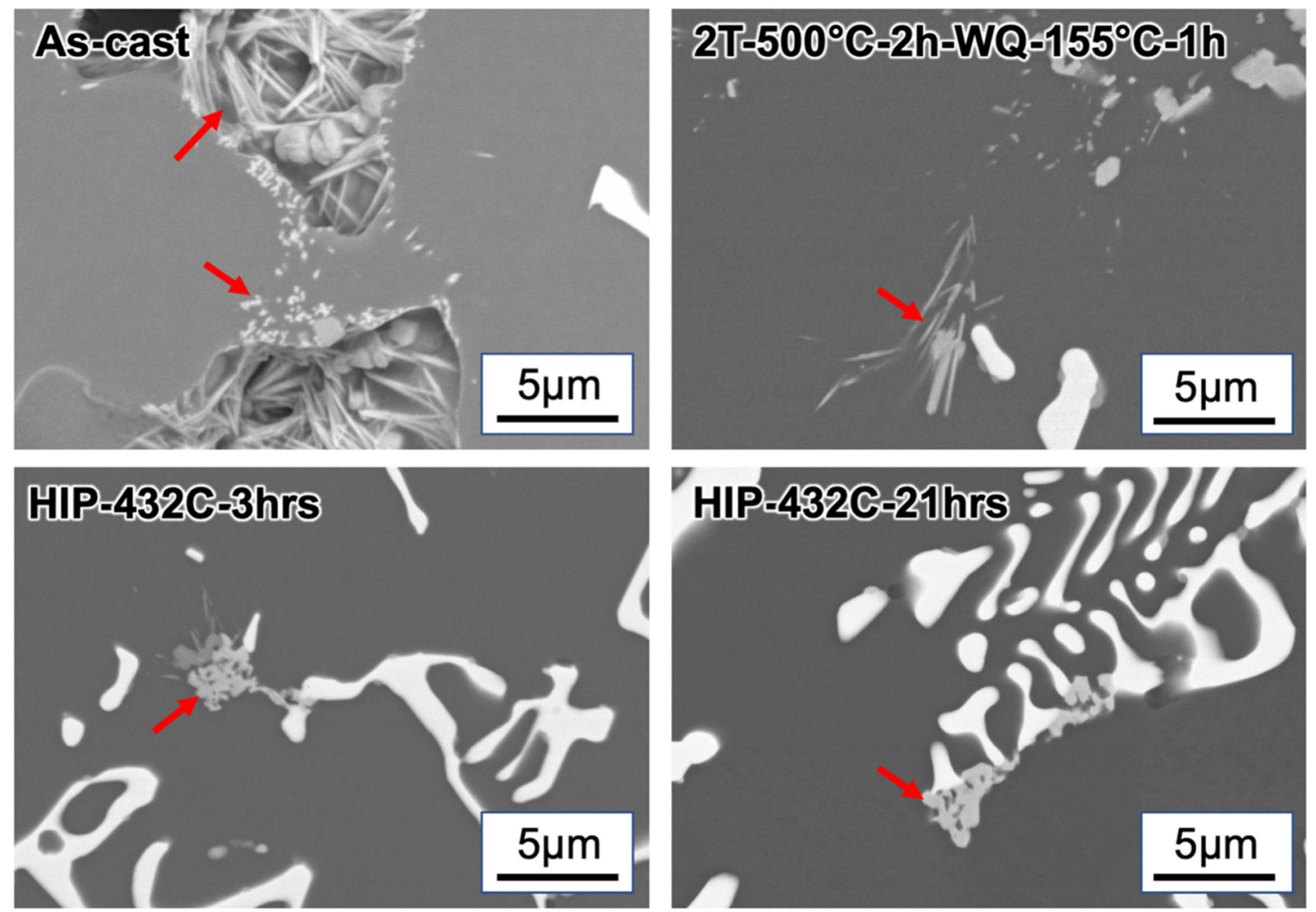

Figure 8. SEM BSE micrographs of alloy Al-8Ce-10Mg showing the effect of processing on the morphology of a Fe-rich phase

assessments of the binary subsystems have been taken from $\mathrm{Al}-\mathrm{Ce},{ }^{11} \mathrm{Al}-\mathrm{Mg},{ }^{12}$ and $\mathrm{Ce}-\mathrm{Mg},{ }^{13}$ while ternary $\mathrm{Al}-\mathrm{Ce}-$ $\mathrm{Mg}$ interactions have been reported in the literature. ${ }^{14} \mathrm{At}$ the solution heat-treating temperatures $\left(500{ }^{\circ} \mathrm{C}\right)$ used in this study, the alloy is almost at its predicted incipient melting temperature $\left(501.13{ }^{\circ} \mathrm{C}\right)$ and is anticipated to be three-phase, $\mathrm{Al}, \mathrm{Al}_{11} \mathrm{Ce}_{3}$, and $\tau\left(\mathrm{Al}_{13} \mathrm{Ce}_{1} \mathrm{Mg}_{6}\right)$ intermetallics. The left plot in Figure 9 does show that between ambient temperature and the solutionizing temperature, an additional $\mathrm{Al}_{140} \mathrm{Mg}_{89}$ compound exists and that the phase fractions undergo large modifications. The overall phase fraction of precipitates evolves from $37.04 \%$ at room temperature to $11.36 \%$ at $500{ }^{\circ} \mathrm{C}$. More specifically, the phase fraction of precipitates involving $\mathrm{Mg}$ (solutionizable element) varies from $29.44 \%$ (room temperature) to $4.91 \%$ $\left(500{ }^{\circ} \mathrm{C}\right)$. This is an equilibrium prediction and does not reflect the kinetics required during a heat treatment cycle to achieve that microstructure once a given room temperature microstructure has developed upon solidification and cooling of the casting. The right plot in Figure 9 highlights 

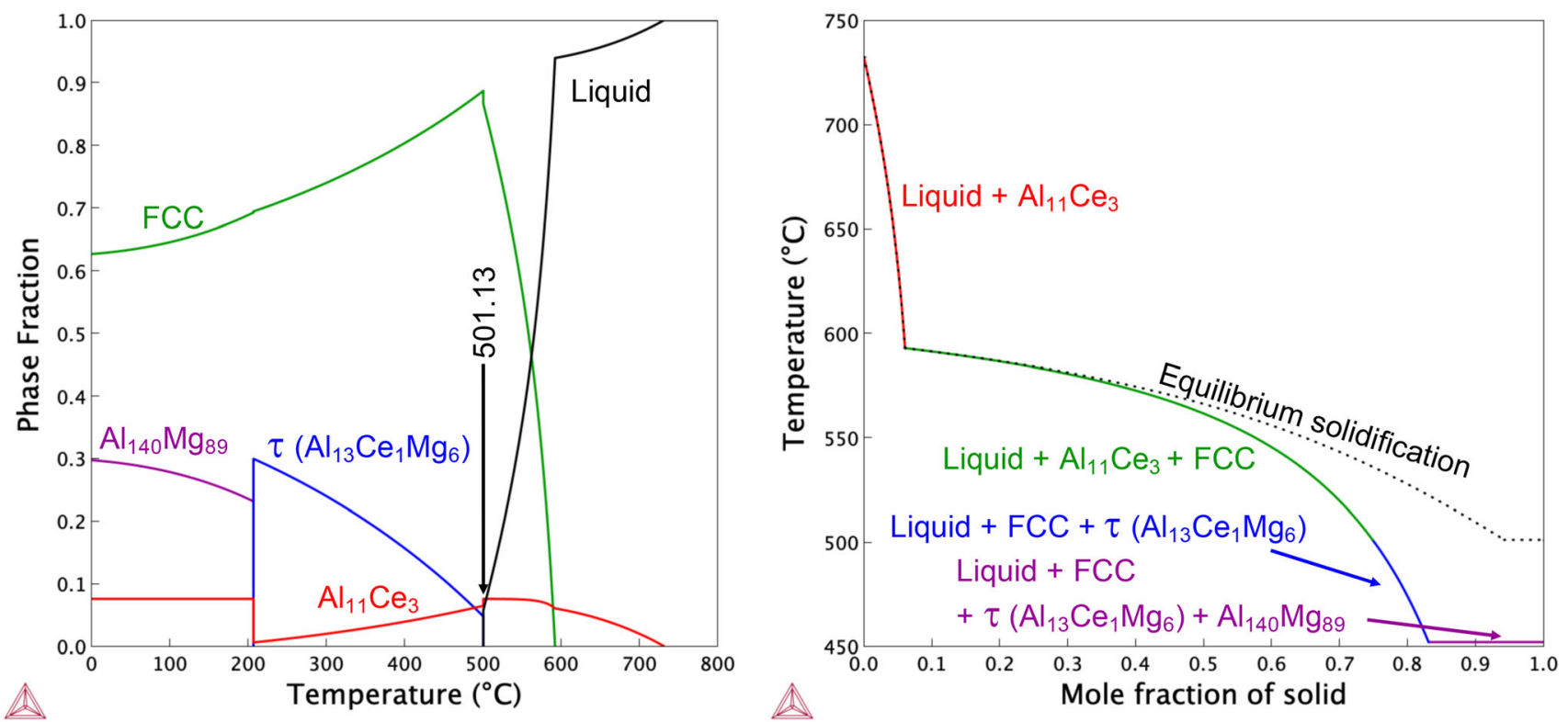

Figure 9. Calculated (left) phase fraction vs temperature and (right) Scheil and equilibrium solidification diagrams for the $\mathrm{Al}-8 \mathrm{Ce}-10 \mathrm{Mg}$ composition

the difference between an equilibrium solidification path (similar to Figure 9 left) and a Scheil solidification path (depictive of casting solidification). As observed, the $\mathrm{Al}_{140} \mathrm{Mg}_{89}$ compound can even form at the end of the Scheil solidification compared to the solid-phase precipitation observed at equilibrium (Figure 9 left) and requires thermal treatment to be dissolved. It is those phases $\left(\mathrm{Al}_{140} \mathrm{Mg}_{89}\right.$ and $\left.\tau\right)$ that need to dissolve to get all, or at least a significant amount, of the solute in solid solution to achieve the maximum strengthening response during the heat treatment cycle. The normally very lengthy solution heat-treating times for $\mathrm{Al}$ alloys reflect the significant time to get some dissolution, and therefore, the thermomagnetic processing appears to accelerate the kinetics during solution heat treating as manifested by increased strength without loss of ductility after heat treatment.

In conclusion, the results of this study on multiple different alloy systems clearly demonstrate that the HMFP technology achieves enhanced room temperature mechanical property performance at shorter processing times compared with conventional heat-treating practices. Of significance from a commercial implementation perspective, magnetic fields on the order of $2 \mathrm{~T}$ appear to exhibit most of the beneficial effects that field strengths up to $9 \mathrm{~T}$ produce, for the $\mathrm{Al}-8 \mathrm{Ce}-10 \mathrm{Mg}$ alloy. This suggests the possibility that the effect of lower field strength on enhanced performance may carry over to other age-hardening $\mathrm{Al}$ alloy systems.

\section{Technology Commercialization Viability}

Since positive results in both heat-treating process energy efficiency and casting performance enhancement have been shown for the different alloy systems using thermomagnetic processing, the viability for potential commercial system designs was evaluated. Initially, performance enhancement was observed using a 9-T magnetic field during heat treatment; thus, a large-bore superconducting magnet system with that high field capability would be necessary. As seen in the concept drawing in Figure 10, a cryogen-free (conduction-cooled) 8-T superconducting high magnetic field system is viable with a 16-in. diameter (406 $\mathrm{mm}$ ) warm bore that would be able to handle both a heating insert and large components.

The work presented here has demonstrated that magnetic field strengths of only $2 \mathrm{~T}$ are necessary to achieve a meaningful benefit. Superconducting system design becomes tremendously easier and significantly less expensive at low field strengths such as $2 \mathrm{~T}$ compared with $8 \mathrm{~T}$ or $9 \mathrm{~T}$. Therefore, the 2-T, 24-in. diameter warm-bore re-condensing cryocooler superconducting magnet design from American Magnetics, Inc., shown in Figure 11 is industrially viable for some applications. That design concept readily allows for increasing the length of the uniform field zone to accommodate samples with industrial-scale dimensions in all directions. Although shown with a horizontal bore, the system could easily be built with a vertical bore to allow rapid dropping of the sample into a quench medium if required or accommodating both a heating and quenching insert in the magnet bore itself. A system shown in Figure 11 would cost nominally $\$ 700 \mathrm{~K}$ to $\$ 800 \mathrm{~K}$. One important aspect of superconducting magnet systems is that they are typically set to persistent mode in operation, a state where the superconducting loop does not require electricity input to continue operation at field. This mode can be set to any field strength from zero 

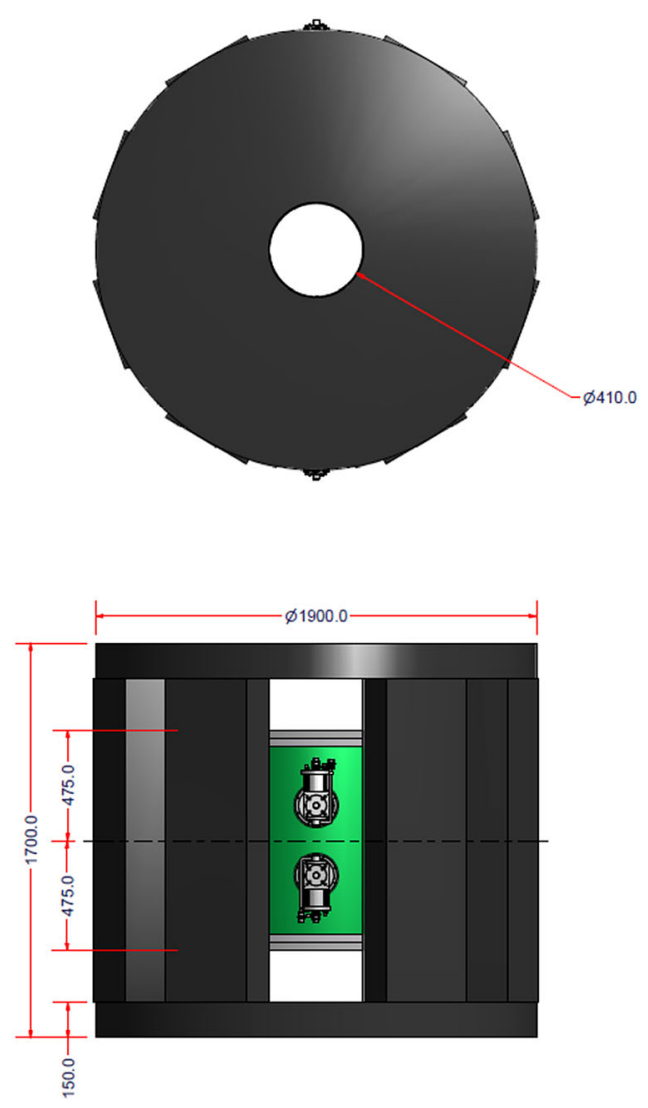
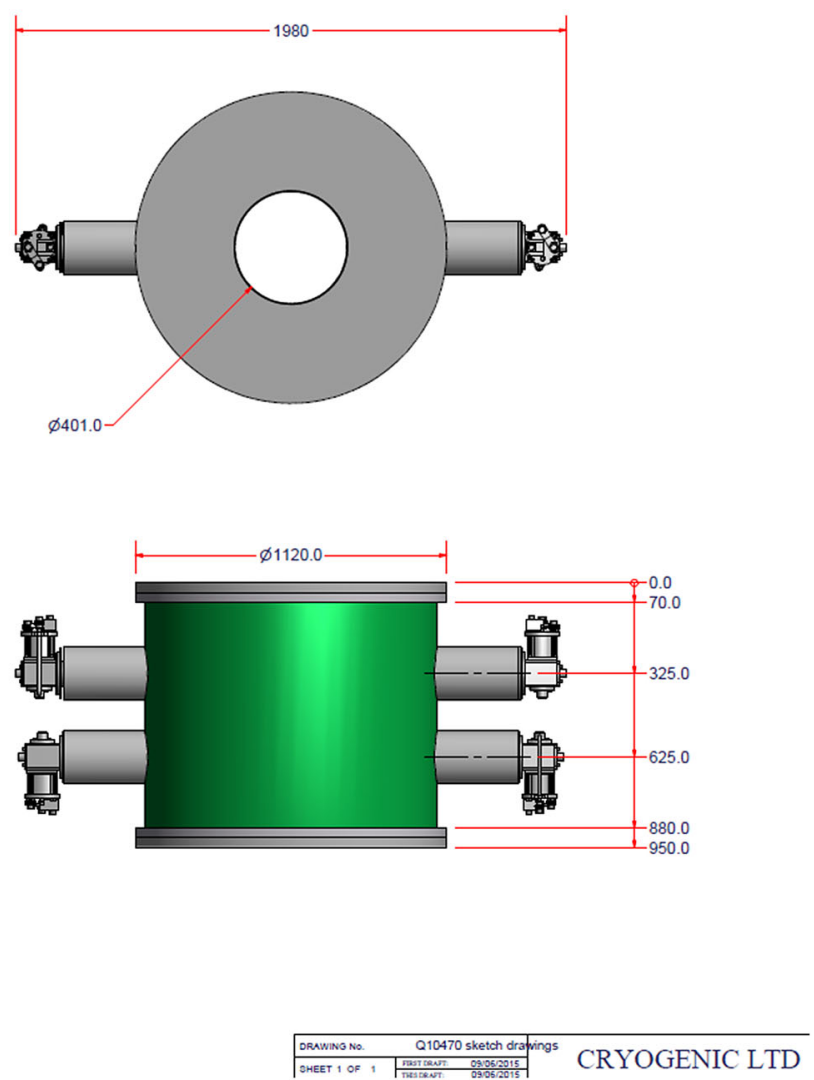

Figure 10. Concept drawing provided by Cryogenic Limited for an 8-T, cryogen-free (conduction-cooled) 16-in. (406 $\mathrm{mm}$ ) diameter warm-bore superconducting magnet system

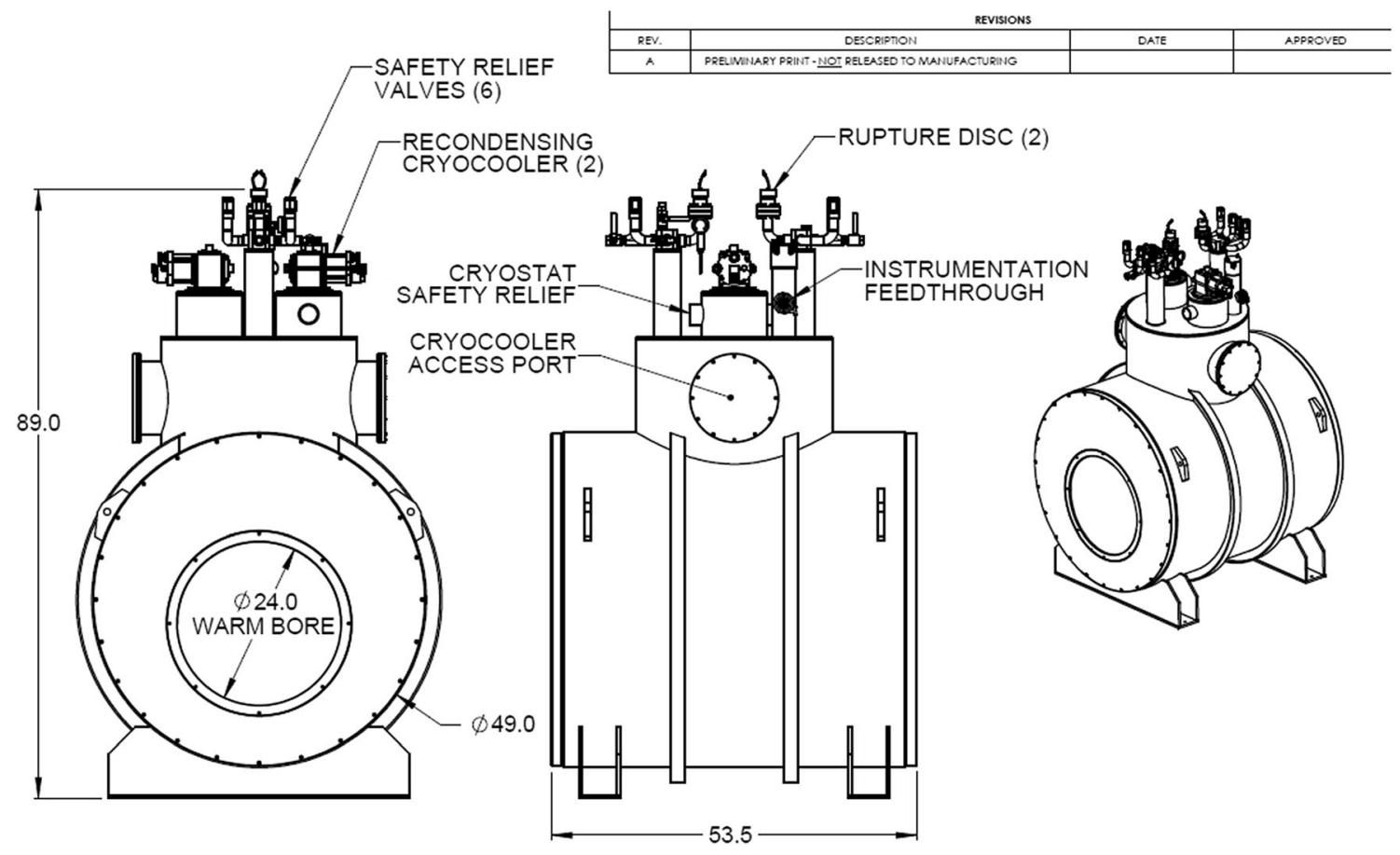

Figure 11. Concept drawing provided by AMI, Inc., for a 2-T, decondensing cryocooler-based, 24-in. $(610 \mathrm{~mm})$ diameter warm-bore superconducting magnet system 
up to their maximum magnetic field design value, so procuring a system capable of higher magnetic field strengths can be used to cover a range of field magnitude needed in a production environment. It should be noted that implementation of TMP into production based solely on energy efficiency may be only marginally beneficial, but the potential for performance improvements otherwise unachievable in combination with efficiency can make the technology compelling in high value applications.

\section{Impacts}

Magnetic processing of $\mathrm{Al}$ castings could create significant savings in the manufacturing of Al castings, especially through heat treatment energy savings of up to $80 \%$ based on reductions in heat treatment times. Additionally, this technology will contribute to transportation fuel savings by enabling lighter weight vehicles with enhanced performance. The results clearly document the enhanced performance and energy savings potential of thermomagnetically processing cast (or wrought) Al alloys during either just the solution heat treatment cycle or both the solution heat-treating and aging process.

\section{Conclusions}

Thermomagnetic processing during solution heat treating and aging of cast $\mathrm{Al}$ alloys $(206,242,355$, and $\mathrm{Al}-8 \mathrm{Ce}-$ $10 \mathrm{Mg}$ ) resulted in yield strength (YS) improvement ranging from 10 to $48 \%$ and ultimate tensile strength (UTS) improvement of $16-37 \%$ over reported conventional values. In addition, all HMFP solution heat-treating and aging times employed in this study were significantly shorter than the conventionally required times. This indicates this technology could achieve significant energy savings when implemented in a production heat-treating environment. Microstructural analyses suggest that the high magnetic fields enable faster dissolution of solute during the solution heat-treating cycle, resulting in finer and more copious strengthening precipitates after the aging cycle. This would explain the increase in YS and UTS without loss of ductility via HMFP. This effect is coupled with limited coarsening and spheroidization, resulting in finer overall microstructure that contributes to the enhanced mechanical properties. Large-bore superconducting magnet systems that could handle production scale parts can be obtained in the marketplace, and as such, commercial implementation of HMFP, especially at the 2-T magnetic field level, can be realized if a return-on-investment calculation supported a path forward for a specific business sector. The results of this study on multiple different Al alloy systems clearly demonstrate that the HMFP technology achieves excellent, enhanced room temperature mechanical property performance at significantly shorter processing times compared with conventional heat-treating practices. Of significance from a commercial implementation perspective, magnetic fields on the order of $2 \mathrm{~T}$ appear to have the same beneficial effect as field strengths up to 5 and $9 \mathrm{~T}$ for the $\mathrm{Al}-$ $8 \mathrm{Ce}-10 \mathrm{Mg}$ alloy which suggests this $2-\mathrm{T}$ magnetic field strength may improve mechanical properties of age-hardening $\mathrm{Al}$ alloy systems for both cast and wrought product.

\section{Acknowledgements}

This work was supported in part by Crada/NFE-1505869 and performed under the auspices of the U.S. DOE with ORNL under contract DE-AC0500OR22725 within the Critical Materials Institute, an Energy Innovation Hub funded by the U.S. Department of Energy, Office of Energy Efficiency and Renewable Energy, Advanced Manufacturing Office. A special thanks to American Magnetics, Inc., for the discussions, magnet drawings, and partnership relating to this work.

Open Access This article is licensed under a Creative Commons Attribution 4.0 International License, which permits use, sharing, adaptation, distribution and reproduction in any medium or format, as long as you give appropriate credit to the original author(s) and the source, provide a link to the Creative Commons licence, and indicate if changes were made. The images or other third party material in this article are included in the article's Creative Commons licence, unless indicated otherwise in a credit line to the material. If material is not included in the article's Creative Commons licence and your intended use is not permitted by statutory regulation or exceeds the permitted use, you will need to obtain permission directly from the copyright holder. To view a copy of this licence, visit http://creativecommons. org/licenses/by/4.0/.

\section{REFERENCES}

1. G.M. Ludtka et al., In situ evidence of enhanced transformation kinetics in a medium carbon steel due to a high magnetic field. Scr. Mater. 51, 171-174 (2004)

2. T.A. Bennett et al., Texture evolution in $\mathrm{Fe}-1 \% \mathrm{Si}$ as a function of high magnetic field. Solid State Phenom. 105, 151-156 (2005)

3. Nicholson et al., The effect of high magnetic field on phase stability in Fe-Ni. J. Appl. Phys. 95(11), 6580-6582 (2004)

4. D. Weiss, Development and casting of high cerium content aluminum alloys, in Transactions of the American Foundry Society (2017), pp. 19-23

5. Z.C. Sims et al., High performance aluminum-cerium alloys for high-temperature applications. Mater. Horiz 4(6), 1070-1078 (2017)

6. Z.C. Sims et al., Cerium-based, intermetallic-strengthened aluminum casting alloy: high-volume co-product development. JOM 68(7), 1940-1947 (2016)

7. G.M. Ludtka et al., Exploring ultra-high magnetic field processing of materials for developing customized microstructures and enhanced performance, in Materials Processing in Magnetic Fields (2005), pp. 55-65 
8. M.S. Kesler et al., Effects of high magnetic fields on phase transformations in amorphous $\mathrm{Nd}_{2} \mathrm{Fe}_{14} \mathrm{~B}$. Magnetochemistry 5(1), 16 (2019)

9. X. Liu et al., Influence of a low-frequency electromagnetic field on precipitation behavior of a high strength aluminum alloy. Mater. Sci. Eng. 402, 1-4 (2005)

10. T. Watanabe et al., A new challenge: grain boundary engineering for advanced materials by magnetic field application. J. Mater. Sci. 41, 7747-7759 (2006)

11. M.C. Gao et al., Re-assessment of Al-Ce and Al-Nd binary systems supported by critical experiments and first-principles energy calculations. Metall. Mater.

Trans. A36, 3269-3279 (2005)
12. Y. Zhong et al., Contribution of first-principles energetics to $\mathrm{Al}-\mathrm{Mg}$ thermodynamic modeling. Calphad 29, 303-311 (2005)

13. C. Guo et al., A thermodynamic description of the $\mathrm{Ce}-$ La-Mg system. Int. J. Mater. Res. 101, 1424-1431 (2010)

14. J. Grobner et al., Thermodynamic modeling of Al$\mathrm{Ce}-\mathrm{Mg}$ phase equilibria coupled with key experiments. Intermetallics 10, 415-422 (2002)

Publisher's Note Springer Nature remains neutral with regard to jurisdictional claims in published maps and institutional affiliations. 